Original Article

\title{
PHARMACIST INTERVENTION ON IDENTIFICATION OF DRUG INTERACTIONS IN TERTIARY CARE HOSPITALS
}

\author{
KAMESWARAN R. ${ }^{* *}$, SHANMUGA SUNDARAM RAJAGOPAL ${ }^{2}$, KRISHNAVENI KANDASAMY1 ${ }^{1}$, KARTHIKEYAN \\ KRISHNAN 1
}

${ }^{1}$ Faculty of Pharmacy, Pacific Academy of Higher Education and Research University, Udaipur 313024, Rajasthan, India, ${ }^{2}$ Department of Pharmacology, J. K. K. Nattraja College of Pharmacy, Kumarapalayam 638183, Tamil Nadu, India

Email: kamesjohashwanth@gmail.com

Received: 10 Jul 2018 Revised and Accepted: 18 Aug 2018

\begin{abstract}
Objective: The aim of this study was to assess the potential drug interactions (pDIs) among hospitalized patients in cardiac and neurology wards in 3 tertiary care hospitals.

Methods: A prospective, observational study was carried out for a period of 12 mo. A sample of 1330 patients was assessed for pDDIs using Micromedex ${ }^{\circledR}$-2.7and drugs.com and www.dugs.com.

Results: A total of 1330 patients were analyzed and it was found that 685 were cardiac and 645 were neurology patients. The study identified 524 (76.49\%) cardiac patients and 425 (65.89\%) neurology patients, with potential drug-drug interactions (pDDIs) higher in male cardiac [298 (56.87\%)] and male neurology [235 (55.29\%)] patients, compared to females. Incidences of pDDIs were found to be higher in the age group of 60 $70 \mathrm{y}$ in cardiac [193 (36.83\%)] and neurology [165 (38.84\%)] patients and incidences of interactions based on duration of (4-6 d) hospital stays in cardiac were $380(72.53 \%)$ and $275(64.70 \%)$ in neurology patients respectively. Moreover, $51.90 \%$ cardiac patients and $57.41 \%$ neurology patients were found to be prescribed with more number of drugs in cardiac and neurology ( 7 drugs) patients, were found to have developed higher incidences of pDDIs. The most common drug interacting pair was between aspirin and clopidogrel combination, observed in 245 cardiac and 316 in neurology patients. Drug-food interactions (DFIs) were found with between atorvastatin-citrus fruits in cardiac and phenytoin-protein rich foods in neurology patients. The most common drug-disease interaction (D-DIs) was found to between isosorbide dinitrate-myocardial infarction in cardiac and carbamazepine-seizuresin neurology respectively.
\end{abstract}

Conclusion: It is recommended that physicians should be aware of the interactions among those drugs while prescribing, and careful monitoring is also required.

Keywords: Cardiac, pDDIs, Neurology, Aspirin and clopidogrel, Carbamazepine-seizures

(C) 2018 The Authors. Published by Innovare Academic Sciences Pvt Ltd. This is an open access article under the CC BY license (http://creativecommons.org/licenses/by/4.0/) DOI: http://dx.doi.org/10.22159/ijpps.2018v10i10.28399

\section{INTRODUCTION}

Drug-drug interactions are defined as two or more drugs interacting in such a manner that the effectiveness or toxicity of one or more drugs is altered [1, 2]. Drug-drug interactions (DDIs) are an important subgroup of Adverse Drug Events (ADE) [3], which are highly prevalent in patients receiving multiple-drug treatment [4]. The majority of the interactions occur because, either prescriber's do not consider them relevant $[5,6]$, or prescriber may be receiving less information in the DDIs area. Polypharmacy, geriatric and patients with co-morbidities are considered as one of the major risk factors in the precipitation of Drug-Drug interactions (DDIs) [5].

Neurological illnesses are one among the most common causes of hospitalization. It is estimated that DDIs account for approximately $2.8 \%$ of hospital admission every year [6]. The issue of drug interactions is a global concern, a study of the US reported that $30.3 \%$ patients aware at risk of DDIs [7]. A recent study in Iran has reported that in $35.5 \%$ of the patients in the neurology department encountered at least one pDDIs (Potential Drug-Drug Interactions) [8]. The burden of neurological disorders in India is estimated at over 30 million, which often warrant complex therapeutic regimen [9]. In India, a study identified $66 \%$ of DDIs in a medicinal department of a tertiary care hospital in Karnataka, India [10], while another study in Chandigarh reported that $8.3 \%$ prescriptions had multiple DDIs [11]. It was estimated that about $46.3 \%$ drug interactions were seen in neurological patients in a cross-sectional study conducted in Karnataka and majority of the DDIs were moderate in severity and required therapeutic monitoring [12]. An exhaustive literature search did not reveal as many published reports on DDIs in neurological disorders in Indian population or other countries, however similar studies in other hospital wards has been done.

The present study was aimed to determine the prevalence and assessment of pDDIs in patients admitted to cardiology and neurology department and to identify pDDIs risk factors. In view of the above-mentioned statistics, we purposefully conducted this study in a tertiary care hospital in Erode as there are no studies targeted this region of the country.

Diet and lifestyle can sometimes have a significant impact on drugs. These may occur out of accidental misuse or due to lack of knowledge about the active ingredients involved in the relevant substances. Interactions between food and drugs may inadvertently reduce or increase the drug effect. Major side effects of some diet (food) on drugs include alteration in the absorption of fatty, high protein and fiber diets. Sixteen cohort and case-control studies reported an elevated risk of hospitalization in patients who were exposed to pDDIs [13]. Studying the drug-drug interactions, drug-food interactions and drug-disease interactions are essential for the management of drug therapy. As per our knowledge, there are no studies were conducted in our study area. Hence we carried out a study to assess the prevalence of drug-drug interactions, drug-food interactions, and drug-disease interactions.

\section{MATERIALS AND METHODS}

The research was conducted in three tertiary care hospitals, the work was reviewed and approved by the Institute Ethics Committee 
(Human Studies), ethics number is $\mathrm{PP} / 2015 / 01$ and hospital approved number is EMC/PhD/0130T15. Erode for a period of 12 mo in the hospitalized cardiac and neurology patients. 1330 patients were taken in for the study, out of these; there were cardiac 685, neurology 645 patients. Exclusion criteria were outpatients and patients less than $18 \mathrm{y}$ of age, medical disability, as well as the patients who are on Ayurveda, Siddha or other alternative systems of medicine. The consent form was obtained from the hospital authority and hospitalized patients. The data were collected from case sheets of hospitalized patients and direct patient interview from cardiac and neurology departments. Demographic information (age and sex), length of hospital stay, main diagnosis, number of drugs and details of comorbidities were obtained from the clinical records. pDDIs were detected using the Drug Interactions Checker within Micromedex ${ }^{\circledR}-2.7$ and www.drugs com

\section{RESULTS}

A total of 1330 patients were admitted in the department of cardiac and neurology during the study period. Among these, 685 were cardiac and 645 were neurology patients. Out of 685 cardiac patients, 524 (76.49\%) had found to be pDDIs. 856 pDDIs were found in 524 cardiac patients. 795 pDDIs were found in 645 neurology patients. Out of which [298 $(56.87 \%)]$ cardiac male and [235(55.29\%)] neurology male was found to be higher pDDIs, compared to females. Incidences of pDDIs were found to be higher in the age group of $60-70 \mathrm{y}$ in cardiac [193(36.83\%)] and neurology [165 (38.84\%)] patients and incidences of interactions based on duration of (4-6 d) hospital stays in cardiac were 380 (72.53\%) and $275(64.70 \%)$ in neurology patients respectively. $51.90 \%$ patients and $57.41 \%$, cardiac and neurology patients prescribed with more than 7 drugs in cardiac and neurology patients were found to have developed higher incidences of pDDIs.

Table 1: Demographic profile of cardiac and neurology patients

\begin{tabular}{|c|c|c|c|}
\hline S. No. & Parameter & Cardiac total no of patients $(n=524)$ & Neurology total no of patients $(n=345)$ \\
\hline \multirow[t]{3}{*}{1.} & Gender wise distribution & & \\
\hline & Male & $298(56.87 \%)$ & $235(55.29 \%)$ \\
\hline & Female & $226(43.13 \%)$ & $190(44.71 \%)$ \\
\hline \multirow[t]{6}{*}{2.} & Age wise distribution & & \\
\hline & $18-30$ & $21(4.00 \%)$ & $31(7.29 \%)$ \\
\hline & $31-45$ & $69(13.17 \%)$ & $56(13.17 \%)$ \\
\hline & $46-59$ & $164(31.29 \%)$ & $125(29.41 \%)$ \\
\hline & $60-70$ & $193(36.85 \%)$ & $165(38.84 \%)$ \\
\hline & Above 70 & $77(14.69 \%)$ & $48(11.29 \%)$ \\
\hline \multirow[t]{4}{*}{3.} & $\begin{array}{l}\text { Number of hospital stay } \\
\text { (In days) }\end{array}$ & & \\
\hline & $<3$ & $83(15.83 \%)$ & $95(22.35 \%)$ \\
\hline & $4-6$ & $380(72.53 \%)$ & $275(64.70 \%)$ \\
\hline & $>7$ & $61(11.64 \%)$ & $55(12.95 \%)$ \\
\hline \multirow[t]{4}{*}{4.} & Number of prescribed drugs per day & & \\
\hline & $<4$ & $94(17.93 \%)$ & $67(15.64 \%)$ \\
\hline & $5-6$ & $158(30.15 \%)$ & $114(26.82 \%)$ \\
\hline & $>7$ & $272(51.90 \%)$ & $244(57.41 \%)$ \\
\hline
\end{tabular}

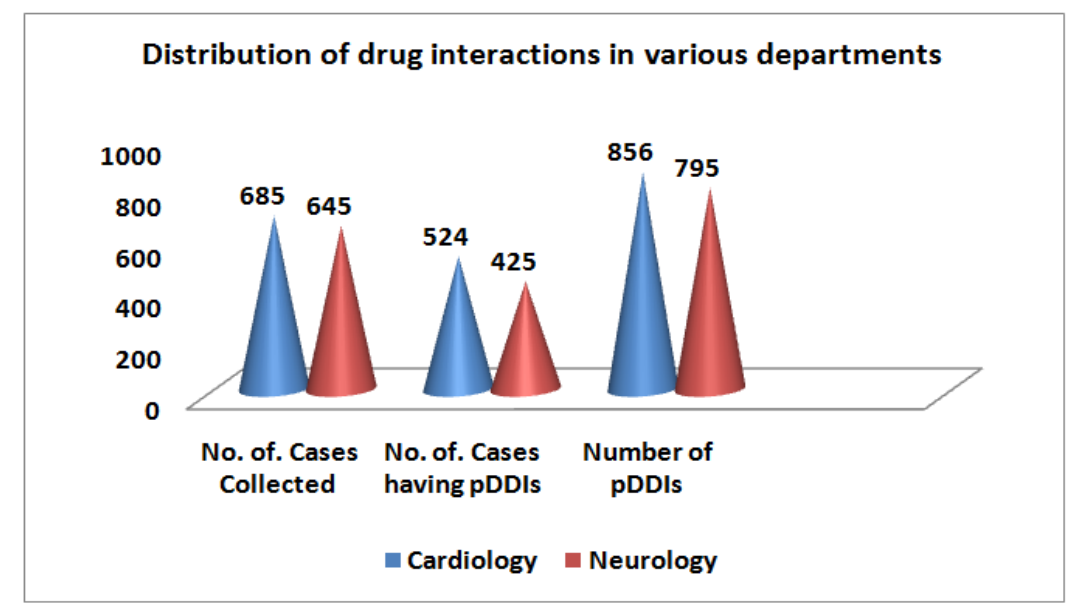

Fig. 1: Distribution of drug interactions in various departments

Table 2: Types of diseases in each department

\begin{tabular}{|c|c|c|c|}
\hline Cardiology $(n=524)$ & & Neurology $(n=425)$ & \\
\hline Type of diseases & No. of. patients & Type of diseases & No. of. patients \\
\hline Myocardial Infarction & $87(16.60 \%)$ & Stroke & $187(44.00 \%)$ \\
\hline Angina+Diabetes mellitus & $111(21.18 \%)$ & Stroke+Alzheimer's disease & $21(04.94 \%)$ \\
\hline Hypertension & $165(31.48 \%)$ & Stroke+Parkinson's disease & $32(07.52 \%)$ \\
\hline Ischaemic Heart Disease & $46(08.77 \%)$ & Stroke+Epilepsy & $43(10.11 \%)$ \\
\hline Coronary Artery Disease & $34(06.48 \%)$ & Epilepsy & $117(27.52 \%)$ \\
\hline Chronic Heart Failure & $81(15.45 \%)$ & Parkinson's disease & $25(05.88 \%)$ \\
\hline
\end{tabular}

On average, each patient had one or two coded diagnoses, in which hypertension was the most common condition165 (31.48\%), followed by Angina with Diabetes mellitus 111(21.18\%) in cardiac patients and Stroke 187 (44.00\%), followed by Epilepsy 117 (27.52\%) in neurology patients (table 2). 
Table 3: Highest potential drug-drug interaction combinations in cardiology

\begin{tabular}{|c|c|c|c|c|}
\hline pDDIs combination & Type & Severity & Frequency $(n=856)$ & Percentage (\%) \\
\hline T. Asprin+T. Clopidogrel & PD & Major & 245 & $28.62 \%$ \\
\hline T. Aspirin+T. Enalapril & PD & Moderate & 69 & $8.06 \%$ \\
\hline T. Atorvastatin+T. Clopidogrel & PK & Moderate. & 78 & $9.11 \%$ \\
\hline T. Aspirin+T. Atenolol & PD & Moderate & 25 & $2.92 \%$ \\
\hline T. Clopidogrel+T. Amlodipine & PK & Moderate & 80 & $9.34 \%$ \\
\hline T. Atenolol+T. Metformin & PK & Major & 25 & $2.92 \%$ \\
\hline T. Spironolactone+T. Enalapril & $\mathrm{PD}$ & Moderate & 18 & $2.10 \%$ \\
\hline T. Enalapril+T. Metformin & Unknown & Major. & 15 & $1.75 \%$ \\
\hline T. Enalapril+T. Furosemide & $\mathrm{PD}$ & Moderate & 12 & $1.40 \%$ \\
\hline T. Aspirin+T. Spironolactone & PD & Major & 41 & $4.78 \%$ \\
\hline
\end{tabular}

Note: $\mathrm{PD}=$ Pharmacodynamics, $\mathrm{PK}=$ Pharmacokinetics

Table 5: Highest potential drug-drug interaction combinations in neurology

\begin{tabular}{|c|c|c|c|c|}
\hline pDDIs combination & Type & Severity & Frequency $(n=795)$ & Percentage (\%) \\
\hline T. Aspirin+T. Clopidogrel & PD & Major & 316 & $39.74 \%$ \\
\hline T. Carbamazepine+T. Phenytoin & PK & Major & 92 & $11.57 \%$ \\
\hline T. Aspirin+T. Metformin & PD & Major & 70 & $8.80 \%$ \\
\hline T. Amlodipine+T. Clopidogrel & PK & Major & 49 & $6.61 \%$ \\
\hline T. Atorvastatin+T. Clopidogrel & PK & Moderate & 37 & $4.24 \%$ \\
\hline T. Clonazepam+T. Theophylline & PD & Moderate & 25 & $3.14 \%$ \\
\hline T. Phenytoin+T. Clonazepam & PK & Moderate & 78 & $9.81 \%$ \\
\hline T. Clobazam+T. Carbamazepine & PK & Minor & 45 & $5.66 \%$ \\
\hline T. Amitriptyline+T. Fluoxetine & $\mathrm{PK}+\mathrm{PD}$ & Major & 42 & $5.28 \%$ \\
\hline T. Diazepam+T. Phenytoin & Unknown & Major & 41 & $5.15 \%$ \\
\hline
\end{tabular}

Table 7: Prevalence of pDDIs

\begin{tabular}{lllc}
\hline S. No. & Type of prevalence & Cardiology & Neurology \\
\cline { 2 - 4 } & Severity of pDDIs & Frequency (n=856) & Frequency (n=795) \\
\hline 1. & Major & $456(53.27 \%)$ & $302(37.98 \%)$ \\
2. & Moderate & $251(29.33 \%)$ & $341(42.89 \%)$ \\
3. & Minor & $149(17.40 \%)$ & $152(19.11 \%)$ \\
\hline
\end{tabular}

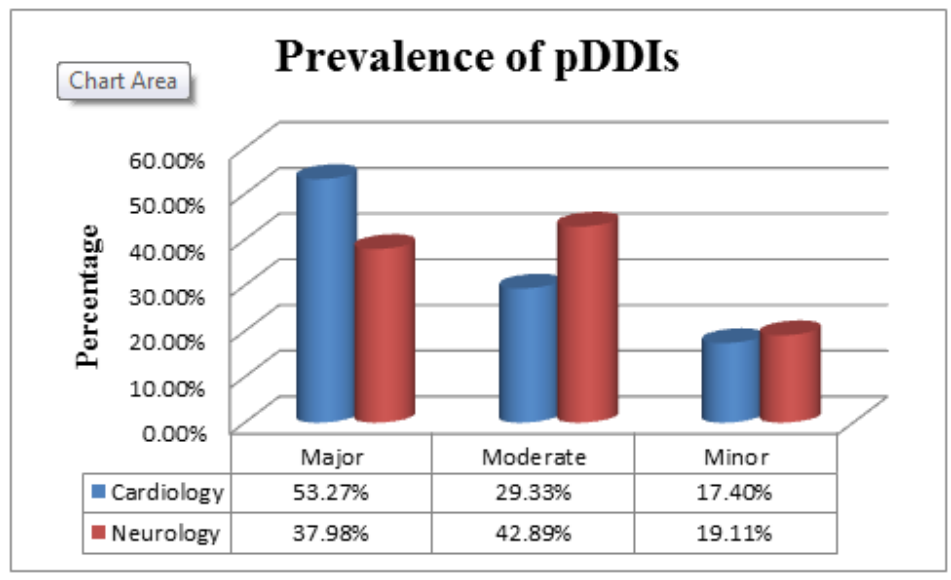

Fig. 2: Prevalence of pDDIs

Table 8: Distribution of potential drug-food interactions in cardiology

\begin{tabular}{|c|c|c|c|c|}
\hline pDFIs & Anticipated effects & $\begin{array}{l}\text { Type of } \\
\text { DFIs }\end{array}$ & Severity & $\begin{array}{l}\text { Frequency } \\
(n=457)\end{array}$ \\
\hline T. Atorvastatin with citrus fruits & Decreased first pass metabolism and increased bioavailability & PK & Moderate & $144(31.50 \%)$ \\
\hline T. Enalapril with Banana & Hyperkalaemia & Unknown & Moderate & $47(10.28 \%)$ \\
\hline T. Atenolol with orange juice & $\begin{array}{l}\text { Decrease the mean peak plasma concentration of atenolol; } \\
\text { excretion of the drug into urine decreased }\end{array}$ & $\mathrm{PK}$ & Moderate & $79(17.28 \%)$ \\
\hline T. Diazepam with Tea/Coffee & $\begin{array}{l}\text { Antagonistic Effect. Caffeine generally antagonized the } \\
\text { diazepam-induced ratings of sedation and impairment of } \\
\text { psychomotor performance }\end{array}$ & PD & Minor & $83(18.16 \%)$ \\
\hline T. Bisacodyl with Milk & Increase the risk of stomach upset and nausea. & Unknown & Minor & $91(19.91 \%)$ \\
\hline T. Paracetamol with Cabbage & Decrease effectiveness of the drug. & $\mathrm{PK}$ & Moderate & $38(8.31 \%)$ \\
\hline
\end{tabular}


Table 9: Distribution of potential drug-food interactions in neurology

\begin{tabular}{|c|c|c|c|c|}
\hline pDFIs & Anticipated effects & Type of DDI & Severity & Frequency $(n=385)$ \\
\hline $\begin{array}{l}\text { T. Phenytoin with Protein Rich Foods } \\
\text { (Fish, Milk, Egg, Meat) }\end{array}$ & Altered Phenytoin concentration & PK & Moderate & $97(25.19 \%)$ \\
\hline $\begin{array}{l}\text { T. Carbamazepine with } \\
\text { Black tea }\end{array}$ & Decreased Carbamazepine bioavailability & PK & Moderate & $65(16.88 \%)$ \\
\hline $\begin{array}{l}\text { T. Acetaminophen with } \\
\text { Cabbage }\end{array}$ & Decreased Acetaminophen Effectiveness & PD & Moderate & $23(5.97 \%)$ \\
\hline T. Diazepam with Tea/Coffee & $\begin{array}{l}\text { Reduced Sedative and Anxiolytic effect of } \\
\text { Diazepam }\end{array}$ & PD & Minor & $45(11.68 \%)$ \\
\hline
\end{tabular}

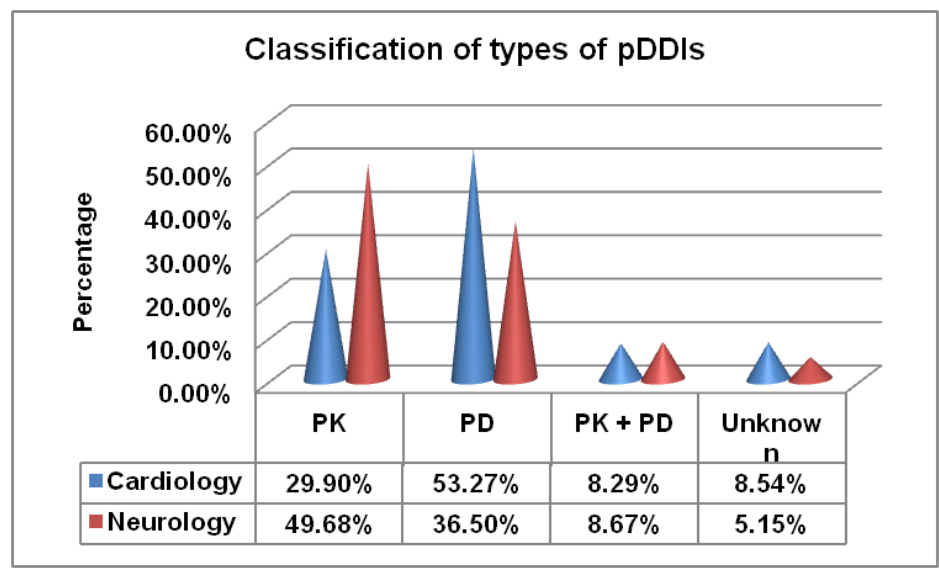

Fig. 3: Classification of types of pDDIs

Table 10: Distribution of potential drug-disease interactions in cardiology

\begin{tabular}{|c|c|c|c|}
\hline pD-DIs & Anticipated effects & Severity & Frequency $(n=289)$ \\
\hline T. ISDN with MI & Systemic hypotension and tachycardia & Major & $42(14.53 \%)$ \\
\hline $\begin{array}{l}\text { Inj. Furosemide } \\
\text { With DM }\end{array}$ & $\begin{array}{l}\text { (latent diabetes may become overt: insulin requirements in established diabetes may } \\
\text { increase: stop furosemide before a glucose tolerance test) }\end{array}$ & Moderate & $56(19.37 \%)$ \\
\hline $\begin{array}{l}\text { T. Atenolol with } \\
\text { DM }\end{array}$ & $\begin{array}{l}\text { Inhibit catecholamine-mediated glycogenolysis, thereby potentiating insulin-induced } \\
\text { hypoglycemia and delaying the recovery of normal blood glucose levels. }\end{array}$ & Major & $24(8.30 \%)$ \\
\hline $\begin{array}{l}\text { T. Enalapril with } \\
\text { CHF }\end{array}$ & $\begin{array}{l}\text { Oliguria and/or progressive azotemia and, rarely, renal failure, myocardial ischemia, and } \\
\text { death. }\end{array}$ & Major & $28(9.68 \%)$ \\
\hline $\begin{array}{l}\text { T. Amlodipine } \\
\text { with CAD }\end{array}$ & Unknown Mechanism & Major & $18(6.22 \%)$ \\
\hline
\end{tabular}

Note: $\mathrm{pD}$-DIs=Potential Drug-disease interactions, ISDN= Isosorbide dinitrate, $\mathrm{MI}=$ Myocardial Infarction, $\mathrm{DM}=\mathrm{Diabetes}$ mellitus, CHF= Congestive heart failure, $\mathrm{CAD}=$ Coronary artery diseases.

Table 11: Distribution of potential drug-disease interactions in neurology

\begin{tabular}{|c|c|c|c|}
\hline pD-DIs & Anticipated effects & Severity & Frequency $(n=215)$ \\
\hline T. Carbamazepine with Seizures & Increased frequency of generalized convulsions & Moderate & $46(21.39 \%)$ \\
\hline T. Atorvastatin with DM & Increased $\mathrm{HbA} 1 \mathrm{C}$ and Fasting blood sugar levels & Moderate & $45(20.93 \%)$ \\
\hline T. Diazepam with seizures & Increased frequency of seizure episodes & Major & $21(9.76 \%)$ \\
\hline T. Telmisartan with DM & Increased risk for new onset of Diabetes & Major & $16(7.44 \%)$ \\
\hline $\begin{array}{l}\text { T. Clopidogrel with } \\
\text { Intracranial Haemorrhage }\end{array}$ & Increased risk of Bleeding & Major & $15(6.97 \%)$ \\
\hline
\end{tabular}

Note: DM= Diabetes mellitus

\section{DISCUSSION}

DIs are a major area of concern these days for the effective management of patient illness. It may create a considerable health hazard to the patients when the risk-benefit ratio of combining interacting drugs is not accurately estimated. It has already been approximated that the effect of drug interactions can range from any minor morbidity to fatal consequences. The study of drug-drug, drug-food, and drug-disease interactions and of genetic factors affecting pharmacokinetics and pharmacodynamics is expected to improve drug safety and will enable individualized drug therapy.
The present study identified a total of 1330 patients were admitted to the department of cardiology and neurology during the study period. Among these, 685 were cardiac and 645 were neurology patients. Out of 685 cardiac patients, 524 (76.49\%) had found to be pDDIs. 856 pDDIs were found in 524 cardiac patients. Our study showed that cardiac male 298 (56.87\%) patients, neurology 235 $(55.29 \%)$ patients had more interactions than female cardiac 226 (43.13\%), neurology 190 (44.71\%), which are similar to the study has shown [14]. Another study has shown [15]. Also reports that male patients are higher cardiology (50.94\%), neurology (54.73\%), and a number of male patients, when compared to females in the 
present study, may be the primary reason. Another reason possibly will be the greatest risk of cardiovascular, neurological disorders among male gender when compared to female and hence there is a need for multiple drugs which ultimately result in drug interactions.

The study the majority of the Incidences of pDDIs were found to be higher in the age group of 60-70 y in cardiac [193 (36.83\%)] and neurology [165 (38.84\%)] patients. A study [16] has reported an age group of 59-69 y, whereas, a study $[17,34]$ has reported that the majority of patients ages were between 70-74 y. Older people are at high risk of developing an ADR due to pDDIs for several reasons. They are likely to have higher comorbidities and thus take several prescriptions and over the counter drugs. As people get older, the liver loses the ability to metabolize drugs. Also, older people are more than twice as susceptible to ADRs as younger people. As people age, the amount of water in the body decreases and the amount of fat tissue relative to water, increases. Also, as people age, the kidneys are less able to excrete drugs into the urine, and the liver is less able to metabolize many drugs.

The study revealed that [380 (72.53\%)] cardiac, [275 (64.70\%)] neurology of patients, and reported that the number of days hospital stay was between 4-6 d (table 1). A study [18], which showed that the majority of the cases, the number of hospital stay were less than $6 \mathrm{~d}$. The likelihood of getting the multiple drugs increases with the increased length of hospital stay which in turn will increase the likelihood of pDDIs.

In our study, $51.90 \%$ cases,per day more than 7 drugs were prescribed in the cardiology department (table 1). The study [19] has shown that $40.60 \%$ cases have been reported as the prescribing between 13 to 16 drugs. $57.41 \%$ neurology department more than 7 drugs were prescribed (table 1); a study [20] has shown, whereas $62 \%$ cases are reported to prescribe more than 8 medications in the neurology department. Similar to another study [21] has reported the concurrent use of three or more drugs increases the risk of ADE's by 9.8 times. More the medications that are prescribed, the more the possibility of irrational polypharmacy. A study [22] has determined the probability of potent cytochrome P450 (CYP 450) interactions in older hospitalized people taking more than five concurrent medicines. Potential drug-drug interactions are present in $80 \%$ of people taking more than 5 concurrent medicines. People taking 5 concurrent medicines have a $50 \%$ probability of at least one drug interaction, each additional medicine adds a $12 \%$ increase in the risk of drug interactions.

The most common interacting pair in the cardiac department in the present study was found to be between aspirin and clopidogrel; which is a major pharmacodynamic interaction, with a frequency of 245 (table 3). The similar study by [23] in which most common interacting pair was identified as aspirin-clopidogrel followed by clopidogrel-Fondaparinux. Another study [24] observed an increased risk of bleeding when aspirin combined with another thrombolytic agent. The most common interacting pair in the neurology department in the present study was found to be between Aspirin and Clopidogrel; which is a major pharmacodynamic interaction, with a frequency of 316 (table 5). This interacting pair increases the risk of bleeding; which is managed by monitoring blood counts. The similar study [25] has reported in which most common interacting pair was identified as aspirin-clopidogrel. Another study [8] which is quite different from this study identifies the most common interacting pair as clopidogrel-omeprazole.

The prevalence of pDDIs in the cardiac department in our study was $53.27 \%$ (table 7). A similar study was [26] showed an overall 77.5\% pDDIs prevalence rate among randomly selected cardiac patients. A study [23] has reported to the department of cardiology showed that the prevalence rate of the bodice was $91.6 \%$ among the studied cardiac patients. The prevalence of pDDIs in the neurology department in our study was $42.89 \%$ (table 7). A similar study [27] in the department of Neurology showed that the prevalence rate of pDDIs was $71.6 \%$ among the patients.

In our study, the prevalence of pDDIs was more in major severity in cardiology. Moderate severity in neurology (table 7). A similar study [28] has reported pDDIs of major severity in 13\% patients and [26] has reported in $24.25 \%$ patients. Prevalence of pDDIs of moderate severity was $30.94 \%$. Another study [24] has reported moderate severity in $60.3 \%$ of patients. This study contrasts the other studies which report moderate severity. These potential DDIs suggest that there is a need for modification or alteration of therapy such as dosage adjustment. In order to prevent these DDIs, health care providers should have adequate information about DDIs not only via drug information center, which can provide evidence-based information to health care professionals, but also through encouraging the empowerment of clinical pharmacists that can provide evidence-based approach to drugs and thereby prevent drug therapy problems of which DDIs is one.

Out of 524 cardiac cases, there was 82 interacting pair identified during the study. Among 856 pDDIs, 256 (29.90\%) were pharmacokinetic interactions, 456(53.27\%) were pharmacodynamic interactions. 71(8.29\%) showing both mechanisms and 73(8.54\%) were the unknown mechanisms. Among 256 pharmacokinetic drug interactions, 39 (15.23\%) were due to absorption, 41 (16.01\%) were due to distribution, $141(55.07 \%)$ were due to metabolism and $35(13.67 \%)$ were due to excretion. Among 456pharmacodynamic interactions, $28(6.14 \%)$ were synergistic, $115(25.21 \%)$ were antagonistic, $294(64.47 \%)$ were additive and 19 (4.18\%) with both additive and antagonistic effects. A similar study [29] has reported, among 423 pDDIs, $50.83 \%$ were pharmacodynamic drug interactions, $38.53 \%$ pharmacokinetic, and $10.64 \%$ showing both kinds of mechanisms. From the 163 pharmacokinetic pDDIs, $45.41 \%$ have altered the absorption, $28.99 \%$ have altered the metabolism, and $25.60 \%$ have altered the excretion. Of the 215 pharmacodynamic pDDIs, $67.44 \%$ were synergistic, $30.70 \%$ antagonistic and $1.86 \%$ unknown in nature. The similar study [34] has reported, the majority being pharmacodynamic interaction is that these types of interactions derive from modification of the action of one drug at the target site by another drug, independent of a change in its concentration. This may result in an enhanced response (synergism), an attenuated response (antagonism) or an abnormal response.

Out of 425 neurology cases, there was 72 interacting pair identified during the study. Among795 pDDIs, 396 (49.68\%) were pharmacokinetic interactions, 289 (36.50\%) were pharmacodynamic interactions. $69 \quad(8.67 \%)$ showing both mechanisms and $41(5.15 \%)$ were the unknown mechanisms. Among 396 pharmacokinetic drug interactions with the neurology department, $282(71.21 \%)$ were due to metabolism. 289 pharmacodynamic interactions, 158 (54.67\%) were Additive which is in contrast with the study by [29], where $67.44 \%$ were synergistically followed by $30.7 \%$ antagonistic.

Diet and lifestyle can sometimes have a significant impact on drugs. These may occur out of accidental misuse or due to lack of knowledge about the active ingredients involved in the relevant substances. Interactions between food and drugs may inadvertently reduce or increase the drug effect. Major side effects of some diet (food) on drugs include alteration in the absorption of fatty, high protein and fiber diets.

According to this study, a total of 1330 patients were admitted to the department of cardiac and neurology during the study period. Among these, 685cardiac patients and 645 neurology patients. Out of 685 cardiac patients, 290 (42.33\%) had found to be drug-food interactions. 457 pDFIs were found in 290 cardiac patients. Out of 645 neurology patients, 235 (34.55\%) had found to be pDFIs. 385 pDFIs were found in 235 neurology patients. The Most of the cardiac cases had pDFIs between atorvastatin-citrus fruits interactions (table 6), with a frequency of 144, which may cause decreased firstpass metabolism and increased bioavailability of atorvastatin that further results in muscle breakdown, liver damage, digestive problems, increased blood sugar and neurological side effects. The reason for these interactions is due to furanocoumarins. The interaction between citrus fruits and medications poses dangers only if a drug is taken orally because the interaction occurs in the digestive tract. The second most common interaction was banana interacting with the ACE inhibitors, with a frequency of 83 , to cause hyperkalemia [30]. Bananas are high in potassium. Too much potassium can cause an irregular heartbeat, and heart palpitations. 
Out of 385 drug-food interactions with the neurology department, 97 cases reported phenytoin with protein-rich foods (fish, milk, egg, meat) (table 7). Moderate, as the drug, must be taken on an empty stomach. This interaction results in altered phenytoin concentrations. A similar study by [31] conducted a study which reported that a simultaneous intake of green vegetables and heparin causes a decreased anticoagulant effect. The total number of drugfood interactions and its prevalence is 230 and $48.42 \%$ respectively.

According to this study, a total of 1330 patients were admitted to the department of cardiac and neurology during the study period and conducted direct patient interview, among these, 685cardiac patients and 645 neurology patients. Out of 685 cardiac patients, 175 (42.06\%) had found to be potential drug-disease interactions. 289 pD-DIs were found in 175 cardiac patients. Out of 645 neurology patients, 148 (35.57\%) had found to be pD-DIs. 215 pD-DIs were found in 148 neurology patients. The most common drug-disease interaction was found to be ISDN with MI (table 8). The interaction may result in systemic hypotension and tachycardia. It may also exacerbate myocardial ischaemia. The second common pD-DIs interaction was found to be furosemide-DM. This interaction may result in latent diabetes may become overt: insulin requirements in established diabetes may increase. So it is advisable to stop furosemide before a glucose tolerance test. The most common pD-DIs in neurology was found to be carbamazepine-seizures (table 9). The interaction may result in increased frequency of generalized convulsions. So it should be used with caution in patients with a mixed seizure disorder that includes atypical absence seizures. The second common pD-DIs was found to be atorvastatin-DM. This interaction may result in increased HbA1C and fasting blood sugar levels. So caution should be exercised when using these agents in diabetic patients and close monitoring is recommended. So it is advisable to stop atorvastatin before glucose test; a contradiction to our study by [32], which reported that the effects of furosemide may contribute to the decrease in glucose utilization.

\section{LIMITATION}

The study was carried out in a hypothetical way of approach to find the prevalence of drug interactions. The active possibilities of DIs respect to the time of drug administration, the half-life of drugs, elimination time were not assessed. The study also could not assess the outcomes of DIs in the selected hospitalized patients.

\section{CONCLUSION}

Our study concluded that the overall incidence of pDDIs was very high in the Department of Cardiology. It was found that the incidence of pDDIs was associated with older age, polypharmacy, increased lengths of hospital stay and increased number of prescribed drugs. DDIs are real with uncertain clinical implications. Therefore, our study highlights the DDIs, which is high among cardiac and neurology patients prescribed with aspirin drug with clopidogrel. Whereas in food-drug interactions in cardiac patients with atorvastatin drug with citrus fruits and neurology patients with phenytoin drug with proteinrich foods and disease-drug interactions in cardiac patients with ISDN drugs with MI, neurology patients with carbamazepine-seizures in a tertiary care teaching hospital. It is recommended that physicians should be aware of the interactions among those drugs while prescribing, and careful monitoring is also required.

\section{ACKNOWLEDGMENT}

I wish to thank management, head of the institution, colleagues, and co-workers in the department of pharmacy practice for their support in the execution of this project work.

\section{AUTHORS CONTRIBUTIONS}

All the author have contributed equally

\section{CONFLICT OF INTERESTS}

The authors declare no conflict of interest

\section{REFERENCES}

1. Peterson JF, Bates DW. Preventable medication errors; identifying and eliminating serious drug interactions. J Am Pharm Assoc 2001;41:159-60.
2. Hamilton RA, Briceland LL, Andritz MH. Frequency of hospitalization after exposure to known drug-drug interactions in a medical population. Ann Pharmacother 1988;18:112-20.

3. Juurlink DN, Mamdani M, Kopp A, Laupacis A, Redelmeier DA. Drug-drug interactions among elderly patients hospitalized for drug toxicity. J Am Med Inform Assoc 2003;289:1652-8.

4. Astrand E, Astrand B, Antonov K, Petersson G. Potential drug interactions during a three-decade study period: a crosssectional study of a prescription register. Eur J Clin Pharmacol 2007;63:851-9.

5. Akram A, Muhammad UK, Irfanul H. Evaluation of potential drug-drug interactions in general medicine ward of teaching hospital in Southern India. J Clin Diagn Res 2015;9:10-3.

6. Becker ML, Kallewaard M, Caspers PW, Visser LE, Stricker BH. Hospitalisations and emergency department visits due to the drug-drug interactions-a literaturereview. Adv Pharmacoepidemiol Drug Saf 2007; 16:641-51.

7. Delafuente JC. Understanding and preventing drug interactions in elderly patients. Crit Rev Oncol Hematol 2003;48:133-43.

8. Namazi S, Pourhatami S, Borhani-Haghighi A, Roosta S. Incidence of potential drug-drug interaction and related factors in hospitalized neurological patients in two Iranian teaching hospitals. Iran J Med Sci 2014;39:515-21.

9. Gourie Devi M. Epidemiology of neurological disorders in India: review of background, prevalence and incidence of epilepsy, stroke, Parkinson's disease and tremors. Neurol India 2014;62:588-98.

10. Shahabudin S, Bharti C, Faizal P. Surveillance of the potential drug-drug interactions in the medicine department of a tertiary care hospital. J Clin Diagn Res 2012;6:1258-61.

11. Kashyap M, D'Cruz S, Sachdev A, Tiwari P. Drug-drug interactions and their predictors: results from Indian elderly inpatients. Pharm Pract 2013;11:191-5.

12. Bose D, Sushma M. Pattern and predictors of drug-drug interactions among the patients admitted in neurology at a tertiary care hospital-a cross-sectional study. Int J Pharm Sci Res 2016;7:3458-64.

13. Hines LE, Murphy JE. Potentially harmful drug-drug interactions in the elderly: a review. Am J Geriatr Pharmacother 2011;9:364-77.

14. Sharma S, Chhetri HP, Alam K. A study of potential drug-drug interactions among hospitalized cardiac patients in a teaching hospital in Western Nepal. Indian J Pharmacol 2014;46:152-6.

15. Murtaza G, Ghani Khan MY, Azhar S, Ali Khan S, Khan TM. Assessment of potential drug-drug interactions and its associated factors in the hospitalized cardiac patients. Saudi Pharm J 2015;43:281-67.

16. Chelkebaa L, Alemsegedc F, Bedadaa W. Assessment of potential drug-drug interactions among outpatients receiving cardiovascular medications at Jimma University specialized hospital, South West Ethiopia. Int J Basic Clin Pharmacol 2013;2:144-52.

17. Fita R, Nurrochmah H, Wasilah R, Syed A. Potentiality of drugdrug interactions in hospitalized geriatric patients in a private hospital, Yogyakarta, Indonesia. Asian J Pharm Clin Res 2010;3:191-4.

18. Lubinga SJ, Uwiduhaye E. Potential drug-drug interactions on in-patient medication prescriptions at Mbarara Regional Referral Hospital (MRRH) in western Uganda: prevalence, clinical importance, and associated factors. Afr Health Sci 2011;11:499-507.

19. de Andrade TNG, Silvestre CC, Cunha LC. Pharmaceutical intervention assessment in the identification and management of drug interactions in an intensive care unit. J Appl Pharm Sci 2015;5:13-8.

20. Dumbreck S, Angela F, Nairn M, Wilson M, Treweek S, Mercer SW. Drug-disease and drug-drug interactions: a systematic examination of recommendations in 12 UK national clinical guidelines. Br Med J 2015;350:949.

21. Mannesse CK, Derkx FH, de Ridder MA, Man in 't Veld AJ, van der Cammen TJ. Contribution of adverse drug reactions to hospital admission of older patients. Age Ageing 2000;29:35-9.

22. Doan J, Zakrzewski-Jakubiak H, Roy J, Turgeon J. Prevalence and risk of potential cytochrome P450-mediated drug-drug 
interactions in older hospitalized patients with polypharmacy. Ann Pharmacother 2013;47:324-32.

23. Murtaza G, Ghani Khan MY, Azhar S, Ali Khan S, Khan TM. Assessment of potential drug-drug interactions and its associated factors in the hospitalized cardiac patients. Saudi Pharm J 2015;43:281-67.

24. Patel VK, Acharya LD, Rajakannan T, Surulivelrajan M, Guddattu V, Padmakumar R. Potential drug interactions in patients admitted to cardiology wards of a south Indian teaching hospital. Australas Med J 2011;4:9-14.

25. Jennifer Diedler, Niaz Ahmed, Marek Sykora. Safety of intravenous thrombolysis for acute ischemic stroke in patients receiving antiplatelet therapy at stroke onset. Stroke 2010;41:288-94.

26. Ismail M, Iqbal Z, Khattak MB, Javaid A, Khan TM. Prevalence, types, and predictors of potential drug-drug interactions in pulmonology ward of a tertiary care hospital. Afr J Pharm Pharmacol 2011;5:1303-9.

27. Aghajani MH, Sistanizad M, Abbasinazari M. Potential drugdrug interactions in post-CCU of a teaching hospital. Iran J Pharm Res 2013;12:243-8.

28. Fokter N, Mozina M, Brvar M. Potential drug-drug interactions and admissions due to drug-drug interactions in patients treated in medical departments. Wien Klin Wochenschr 2010;122:81-8.
29. Chavda N, Solanky P, Baria H, Naik R, Bharti K. Study of potential drug-drug interaction between prescribed drugs in patients attending outpatient department of medicine at tertiary-care hospital in south Gujarat region. Natl J Physiol Pharm Pharmacol 2015;5:236-42.

30. Avoid food and drug interaction. Available from: www.fda.gov/downloads/drugs/resourcesforyou/consumers/ buyingusingmedicinesafely/ensuringsafeuseofmedicine/gener aluseofmedicine/ucm229033.pdf. [Last accessed on 10 Jun 2010].

31. Anila KN, Emmanuel J. Clinical pharmacist governed anticoagulation service stroke unit of a tertiary care teaching hospital. Int J Pharm Res Bio-sci 2013;6:149-52.

32. Dimitriadis G, Tegos C, Golfinopoulou L, Roboti C, Raptis S. Furosemide-induced hyperglycaemia: the implication of glycolytic kinases. Horm Metab Res 1993;25:557-9.

33. Kameswaran Ramalingam, Shanmuga Sundaram Rajagopal, Krishnaveni Kandasamy, Karthikeyan Krishnan. Assessment of potential drug interactions among hospitalized patients at the cardiac and pulmonary departments in tertiary care hospitals. Asian J Pharm Clin Res 2018;11:443-9.

34. Athira Jith, Chaithanya T Kumar, Joffey Sara Joy, Kavitha Samy P, Sambath Kumar R. A prospective study of drug-drug interactions and adverse drug reactions among stroke patients in a tertiary care hospital. Asian J Pharm Clin Res 2016;9:100-4. 